\title{
Impact of Sleep Quality on the Association Between Unease and Physical Exercise During Initial Stages of COVID-19 Pandemic in India
}

This article was published in the following Dove Press journal: Nature and Science of Sleep

\author{
Sahil Bajaj $\mathbb{D}^{1,2}$ \\ Karina S Blair ${ }^{1,2}$ \\ Ru Zhang ${ }^{1,2}$ \\ Johannah Bashford-Largo ${ }^{1,2}$ \\ Matthew Dobbertin ${ }^{1,2}$ \\ $R$ James Blair ${ }^{1,2}$ \\ 'Multimodal Clinical Neuroimaging \\ Laboratory (MCNL), Center for \\ Neurobehavioral Research, Boys Town \\ National Research Hospital, Boys Town, \\ NE, USA; ${ }^{2}$ Program for Trauma and \\ Anxiety (PTAC), Center for \\ Neurobehavioral Research, Boys Town \\ National Research Hospital, Boys Town, \\ NE, USA
}

Correspondence: Sahil Bajaj

Center for Neurobehavioral Research, Boys Town National Research Hospital, I40I5 Flanagan Blvd. Suite \#102, Boys Town, NE, USA

Email sahil.bajaj@boystown.org
To slow the spread of the COVID-19 pandemic, voluntary nationwide lockdowns have been implemented around the globe. One of the biggest COVID-19 initial lockdowns was enforced in India on March 25th, 2020 and lasted for 21 days. Although published data during the COVID-19 pandemic are currently lacking from India, there have been recent suggestions that the impact of this pandemic may vary across demographic (eg, age, sex and marital status) differences. ${ }^{1,2}$ The COVID-19 pandemic and the associated lockdowns have caused unease and a negative impact on people's sleep and routine physical activities. ${ }^{3,4}$ Moreover, feelings of stress and poor sleep quality are both associated with reductions in physical activity. ${ }^{5,6}$ To our knowledge, no work has examined the extent to which sleep quality mediates the association between self-perceptions of stress and level of physical activity during this pandemic. The current study aims to determine (i) potential relationships between the individual's current unease and sleep quality, specifically during the COVID-19 lockdown, and demographical parameters; and (ii) the extent to which sleep quality mediates the association between the individual's unease and level of physical exercise during the pandemic lockdown. A websurvey $(\mathrm{N}=391$; age: $43.22 \%$ aged 19 to 29 years, $27.37 \%$ aged 30 to 35 years, $15.35 \%$ aged 36 to 41 years, and $14.07 \%$ older than 41 years; sex: $53.45 \%$ females; marital status: $53.96 \%$ married) was conducted during the initial 21 days of the pandemic lockdown in India. The details about the study and the survey link were openly shared on several social media platforms targeting current Indian nationals residing in India. Two self-report questionnaires were designed to quantify participants' unease (Cronbach's alpha $=0.78$ ) and sleep quality (Cronbach's alpha $=$ 0.63) during the COVID-19 lockdown. Detailed statements/questions included in these questionnaires are summarized in Table 1. Participants were also asked if they were exercising more to stay fit during the lockdown. Any current Indian resident aged 19 years or older was eligible for the study. Online consent was obtained from all participants. Participation was completely voluntary, and participants were not paid for their time. All procedures followed were in accordance with the ethical standards of the Boys Town National Research Hospital (BTNRH) on human experimentation and with the Helsinki Declaration of 1975, as revised in 2000. The study was approved by the IRB at BTNRH (IRB protocol \# 20-04-X). 
Table I Questions/Statements Included in Unease and Sleep Quality Questionnaire

\begin{tabular}{|c|c|}
\hline \multicolumn{2}{|c|}{ Unease Questionnaire (Reverse Scaled) } \\
\hline 1 & I feel comfortable \\
\hline 2 & I feel relaxed \\
\hline 3 & I feel happy \\
\hline \multicolumn{2}{|c|}{ Sleep Quality Questionnaire (Reverse Scaled) } \\
\hline 1 & I sleep less \\
\hline 2 & I feel headachy \\
\hline 3 & I feel that my sleep-wake cycle is affected now \\
\hline 4 & I feel tired \\
\hline 5 & I feel ill \\
\hline
\end{tabular}

Standard multivariate analysis of variance was performed to determine the differences in unease and sleep quality across age, sex and marital status. A standard mediation analysis (bootstrap samples $=10,000$ ) was conducted using the Hayes PROCESS program (version 3.5) (https://www.processmacro.org/download.html) in SPSS (version 25) to determine whether sleep quality mediated the association between magnitude of unease and physical exercise. Initial covariate analyses revealed significant: (i) sex differences in unease and sleep quality $(\mathrm{F}(1387)=$ -6.24 and 17.50 , partial $\eta^{2}=0.02$ and $0.04, p=0.013$ and $\mathrm{p}<0.001$, respectively); males showed less unease and greater sleep quality; and (ii) marital status differences in unease $\left(F(1387)=5.06, p=0.02\right.$, partial $\left.\eta^{2}=0.01\right)$; unmarried/single participants showed less unease than married participants. There were no significant differences in either unease or sleep quality measures (covariates: sex and marital status) across age groups. Lower levels of uneasiness were significantly associated with both greater sleep quality $(\mathrm{r}=-0.31, \mathrm{p}<0.001)$ and greater levels of physical exercise $(r=-0.10, p=0.04)$. Here, sex and marital status were used as covariates. Sleep quality was also independently associated with greater levels of physical exercise $(r=0.12, p=0.02)$. For this analysis, sex, marital status, and levels of uneasiness were used as covariates. A standard mediation analysis (with sex and marital status as covariates) revealed that while unease during the COVID-19 pandemic was negatively associated with levels of physical exercise (total effect (path c), $B=-0.05, p=0.04$ ), this association disappeared once sleep quality was included as a mediating factor (direct effect (path c'), $B=-0.03, p=0.24$ ). The bootstrap confidence interval for the indirect effect $(a b=-0.02$;
[-0.037 -0.002] 95\% CI) did not include zero. Lower beta coefficients for the paths $\mathrm{b}$ and $\mathrm{c}$ indicate that other variables also influence physical exercise levels - sleep quality is just one significant contributor to physical exercise level. Figure 1 illustrates the path model (model 4) used to test the mediation effect of sleep quality on the association between unease and levels of physical exercise.

The current data indicated that females and married participants are at increased risk of feeling uneasy during a stringent pandemic lockdown. With respect to sex, this may reflect putative greater stress responsivity in females ${ }^{7}$ or the increased social burdens that many experience in the home. ${ }^{8,9}$ With respect to marital status, while there are data to indicate that under typical circumstances married status is associated with reduced stress responsiveness, ${ }^{10}$ data also indicate that the impact of external stressors (potentially such as concern over a pandemic) often becomes exaggerated within a married couple and significantly increase interspouse conflict. ${ }^{11}$ In addition, the stress of prolonged enforced proximity faced by spouses could contribute to increased feelings of unease during stringent lockdowns.

Lastly, but importantly, the current data revealed that the association between unease and levels of physical exercise is mediated by sleep quality. A negative association between stress/unease levels and sleep quality has been documented previously. ${ }^{12,13}$ There have also been data that, relative to individuals with good sleep quality, individuals with poor sleep quality had less energy to engage in physical activities, ${ }^{14}$ a decrease in maximal oxygen uptake, ${ }^{15}$ and a decreased probability that they would meet their exercise goals. ${ }^{16}$ Reduced sleep quality has been found to damage muscle physiology and impair muscle recovery due to greater protein degradation and disrupted protein synthesis. ${ }^{17}$ In short, we believe sleep quality mediates the relationship between unease and physical exercise because increased unease disrupts sleep and decreased sleep quality negatively influences the individual's ability to engage in physical exercise.

The current findings suggest the important benefits of reducing levels of uneasiness either via pharmacological intervention or possibly through non-pharmacological interventions such as cognitive-behavioral therapy or morning blue-light therapy. These benefits include increased sleep quality which, in turn, may significantly increase the individual's ability to engage in physical exercise leading to additional health benefits. Indeed, the current study stresses the importance of attention to sleep 


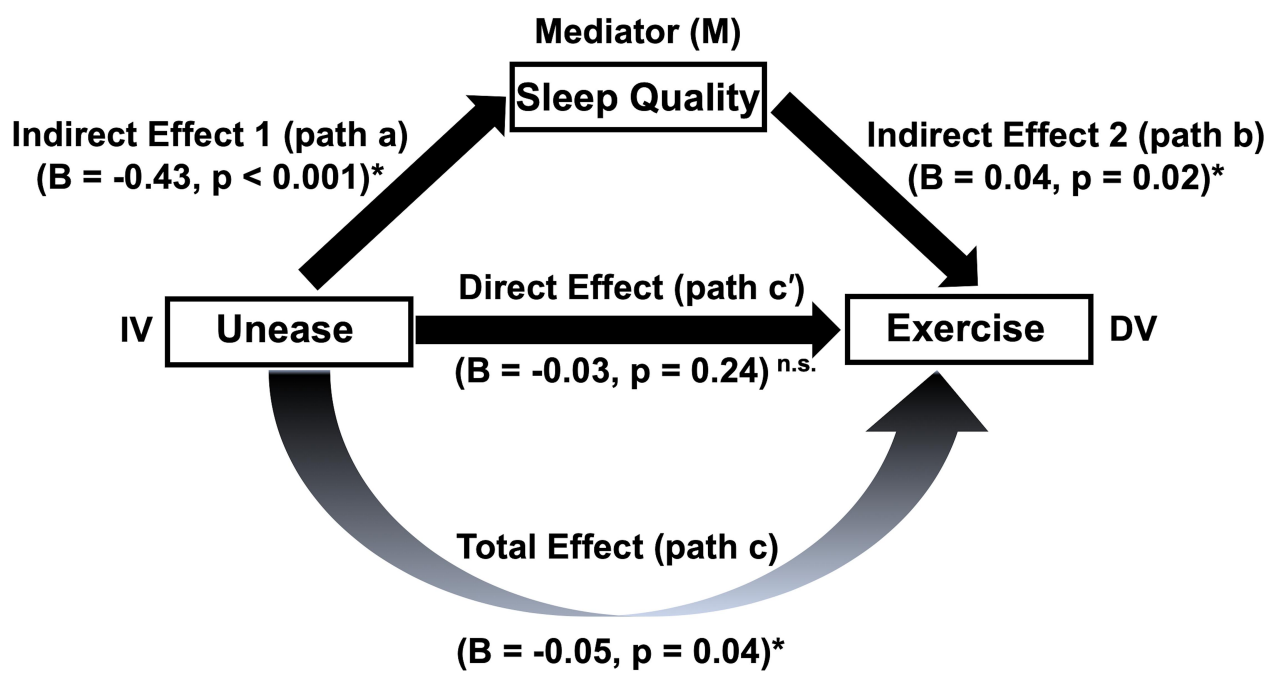

Figure I Mediation Analysis. An illustration of the path model (model 4) used to test the mediation effect of sleep quality (M) on the association of unease (independent variable, IV) with levels of physical exercise (dependent variable, DV). Path model shows complete mediation effect of sleep quality. B, unstandardized beta coefficients; * $p$, 0.05 .

Abbreviation: n.s., non-significant.

quality during stressful times - targeted interventions to increase sleep quality should confer significant benefits to the individual.

Two limitations must be considered regarding the current study: First, the current sample size was small. However, the current study's goal was to determine the impact of sleep quality during the initial stages of the COVID-19 pandemic. As such, data collection was focused on the 21 days of initial lockdown in the country (ie, before people became accustomed to the stringent lockdown). Notably, even this relatively small sample was sufficient to detect a mediating role of sleep quality on the relationship between levels of unease and physical exercise. Second, the current study utilized self-designed scales to quantify the levels of unease and sleep quality. These scales may make the results difficult to compare with other studies. However, in the current study, participants were not paid for their time. Therefore, the self-designed scales were designed to be short relative to standard scales. Future work should focus on a relatively larger sample size and utilize additional standard behavioral scales to determine the contributing factors that may encourage the general public to get engaged in physical activities during stressful times.

\section{Acknowledgments}

Authors would like to thank all the participants for their contribution to this research project. The authors would also like to thank Ramandeep Sharma, Dr. Sumana Ghosh, and Dr. Avinash Bajaj for their inputs and help in data collection.

\section{Disclosure}

The authors report no conflicts of interest.

\section{References}

1. Wang C, Pan R, Wan X, et al. Immediate psychological responses and associated factors during the initial stage of the 2019 coronavirus disease (COVID-19) epidemic among the general population in China. Int $J$ Environ Res Public Health. 2020;17(5):E1729. doi:10.3390/ijerph17051729

2. Badahdah AM, Khamis F, Al Mahyijari N. The psychological well-being of physicians during COVID-19 outbreak in Oman. Psychiatry Res. 2020;289(113053). doi:10.1016/j.psychres.2020.113053

3. Blume C, Schmidt MH, Cajochen C. Effects of the COVID-19 lockdown on human sleep and rest-activity rhythms. Curr Biol. 2020;30 (14):R795-R797. doi:10.1016/j.cub.2020.06.021

4. Tison GH, Avram R, Kuhar P, et al. Worldwide effect of COVID-19 on physical activity: a Descriptive Study. Ann Intern Med. 2020. doi:10.7326/M20-2665

5. Schultchen D, Reichenberger J, Mittl T, et al. Bidirectional relationship of stress and affect with physical activity and healthy eating. $\mathrm{Br}$ $J$ Health Psychol. 2019;24(2):315-333. doi:10.1111/bjhp.12355

6. Kline CE. The bidirectional relationship between exercise and sleep: implications for exercise adherence and sleep improvement. Am J Lifestyle Med. 2014;8(6):375-379. doi:10.1177/1559827614544437

7. Kelly MM, Tyrka AR, Anderson GM, Price LH, Carpenter LL. Sex differences in emotional and physiological responses to the trier social stress test. $J$ Behav Ther Exp Psychiatry. 2008;39(1):87-98. doi:10.1016/j.jbtep.2007.02.003

8. Rao AH. Stand by your man: wives' emotion work during men's unemployment. J Marriage Fam. 2017;79(3):636-656. doi:10.1111/ jomf. 12385

9. Schneider D, Harknett K, McLanahan S. Intimate partner violence in the great recession. Demography. 2016;53(2):471-505. doi:10.1007/ s13524-016-0462-1 
10. Chin B, Murphy MLM, Janicki-Deverts D, Cohen S. Marital status as a predictor of diurnal salivary cortisol levels and slopes in a community sample of healthy adults. Psychoneuroendocrinology. 2017;78:68-75. doi:10.1016/j.psyneuen.2017.01.016

11. Timmons AC, Arbel R, Margolin G. Daily patterns of stress and conflict in couples: associations with marital aggression and family-of-origin aggression. J Fam Psychol. 2017;31(1):93-104. doi:10.1037/fam0000227

12. Åkerstedt T. Psychosocial stress and impaired sleep. Scand J Work Environ Health. 2006;32(6):493-501. doi:10.5271/sjweh.1054

13. Kim EJ, Dimsdale JE. The effect of psychosocial stress on sleep: a review of polysomnographic evidence. Behav Sleep Med. 2007;5 (4):256-278. doi:10.1080/15402000701557383
14. Holfeld B, Ruthig JC. A longitudinal examination of sleep quality and physical activity in older adults. J Appl Gerontol. 2014;33 (7):791-807. doi:10.1177/0733464812455097

15. Chen HI. Effects of 30-h sleep loss on cardiorespiratory functions at rest and in exercise. Med Sci Sports Exerc. 1991;23(2):193-198. doi:10.1249/00005768-199102000-00008

16. Lentino CV, Purvis DL, Murphy KJ, Deuster PA. Sleep as a component of the performance triad: the importance of sleep in a military population. US Army Med Dep J. 2013;98-108.

17. Dattilo M, Antunes HKM, Medeiros A, et al. Sleep and muscle recovery: endocrinological and molecular basis for a new and promising hypothesis. Med Hypotheses. 2011;77(2):220-222. doi:10.1016/j.mehy.2011.04.017

\section{Publish your work in this journal}

Nature and Science of Sleep is an international, peer-reviewed, open access journal covering all aspects of sleep science and sleep medicine, including the neurophysiology and functions of sleep, the genetics of sleep, sleep and society, biological rhythms, dreaming, sleep disorders and therapy, and strategies to optimize healthy sleep.
The manuscript management system is completely online and includes a very quick and fair peer-review system, which is all easy to use. Visit http://www.dovepress.com/testimonials.php to read real quotes from published authors. 